Vol 4, No 1 (2021): Stadium - Hungarian Journal of Sport Sciences

https://doi.org/10.36439/shjs/2021/1/9535

\title{
THE RELATIONSHIP BETWEEN DECISION-MAKING AND GAME INTELLIGENCE WITH BASKETBALL STATISTICS
}

\author{
Kata Németh1, László Balogh \\ ${ }^{1}$ University of Pécs Doctoral School of Health Sciences. Pécs, Hungary. \\ ${ }^{2}$ University of Debrecen, Institute of Sport Sciences, Debrecen, Hungary
}

\begin{abstract}
Introduction: basketball is one of the most popular team sport worldwide. It is generally regarded as the second most popular sport globally, with around 450 million registered players (RÁTGÉBER et al., 2019). The attention, decision-making, interaction with the participants, and recovery of a basketball player are complex. It can be influenced by internal and external factors as well as by different stimuli. The current mental and physical state of athletes affects their performance. Experience, reception and adaptation of developmental stimuli determine performance during the game. Cognitive abilities, executive functions, and inhibition are all psychological processes that can help or hinder concentration. It is essential to assess and measure to enhance sports performance and provide objective support for our subjective assumptions. Many technical and tactical elements characterizes basketball, but it is also essential to have relevant motor and affective skills when making decisions. Players need to adapt to sudden and varied stimuli and make the most intelligent and appropriate decision to achieve a positive outcome. Live statistics may indicate the effectiveness of decision-making during the game. In the present study, we analyzed the results of the Color-Word Interference Test and Trail Making Test prior and after the games.
\end{abstract}

Keywords: attention, decision, arousal, intelligence, basketball statistics, Stroop-test, Color-Word Interference Test, Trail Making Test

\section{THEORETICAL BACKGROUND}

\section{ATTENTION}

At any given moment in our lives, there are almost countless stimuli that affect our senses. Attention can be aroused by any intense, unexpected, unusual stimulus (BARTHA, 1978). Focusing attention is crucial in any performance domain (TEDESQUI-GLYNN, 2013). Attention is considered a vital aspect of sports performance, a central component of skill learning and enhancing expert performance (ABERNETHY, 2001; BOUTCHER, 2008). The ability to focus directly influences the psychological elements necessary for superior performance, such as mental preparedness and control of distraction (ORLICK, 2008). According to Carr and Hinckley (2012) attention is divided into three systems: (1) attentional arousal and vigilance, which prepares the individual to perform a task; (2) orientation and selection towards information sources from the external world and memory (selective attention system); (3) temporary maintenance and manipulation of information, including shifting the focus of attention (working memory). Furley and 
Memmert (2010) tested experienced basketball players compared to non-athletes. Their research showed that the basic cognitive abilities of the two groups did not differ. The only exception is attention. There was no difference in spatial capacity. Nideffer characterized attentional focus along two dimensions: (1) scope, broad or narrow; (2) orientation, internal or external. Based on these, sport profiles can be created (BALOGH, 2015). According to Wulf (2007), an individual's attention when performing motor skills is called the internal focus, directed towards his/her movement.

In contrast, we speak of external focus when individuals' attention is directed to the effects of the movement. Research shows that outward focus, as opposed to internal focus, increases performance. Play situations are characterized by continuous and changing demands on attention (TEDESQUI-GLYNN, 2013). Beilock and colleagues (2001, 2002) have extensively shown that the appropriate focus varies according to different types of tasks and levels of expertise. Several studies have demonstrated that well-learned skills should be performed under the control of automatic processing, i.e., without consciously thinking about the processes involved in their performance.

\section{DECISION}

Making the right decision is based on several things. Technical and tactical factors influence the effectiveness of the given throw. Both cognitive strategy and decisionmaking skills can be developed. Coaching and playing experience influence decisionmaking style (BÍRÓ-BALOGH, 2020). Players' decisions have an immediate result. Decisions directly influence the outcome of gamees and competitions (MCCLUNEY et al., 2020). The decision-maker affects the quality of the decision in positive, neutral, and negative aspects (LABORDE-RAAB, 2013). It is not enough that players are equipped with skills; they must be in the so-called zone at the most critical moment of the game (momentum) (BALOGH, 2021).

Previous research suggests that feeling in the zone is vital when the demand of the task gamees the player's skill level (KENNEDY et al., 2014). The concept and nature of the zone have emerged as a critical concept of peak performance in sport (BALOGH, 2014). The hallmark of a good player is to play well when the stakes are highest (success-oriented player). If an individual's nervous system is stimulated correctly, it will adapt. An optimal external load will result in an internal load associated with fatigue, recovery, and supercompensation for the athlete's body. Training exercises must affect the nervous system because this is the only way to develop it (BALOGH, 2021). The cognitive and emotional states generated by dynamic playing conditions induce mental efficiency, intrinsic motivation, focus, and control in players, in the entire playing environment. Increasing difficulty and immersive games provide opportunities for choice, action, and influence on the course of the game (YELAMANCHILI, 2018). Basketball is a complex sporting activity in terms of speed and control of information processing and decisionmaking per unit of time. Mental strain can be caused by self-expectation, the extent of 
preparation, and the significance of results (MCCLUNEY et al., 2020). Decision-making involves different elements: perception, attention, thinking, learning, motor skills, technical-tactical preparedness, stress, and psycho-physiological-motor factors (Fig. 1). Experience has a significant impact on the speed and success of the decision (BALOGHDONKA, 2020). Experienced athletes make better decisions more often. It is not his/her perception that is faster, but he/she starts to recognize the situation before the decision has arisen. If there is proficiency in certain game situations, it can lead to better and faster decisions. In basketball, stimuli come quickly; a decision already made influences the next one. The consequences of a given decision will impact the following game situation (BALOGH, 2021).

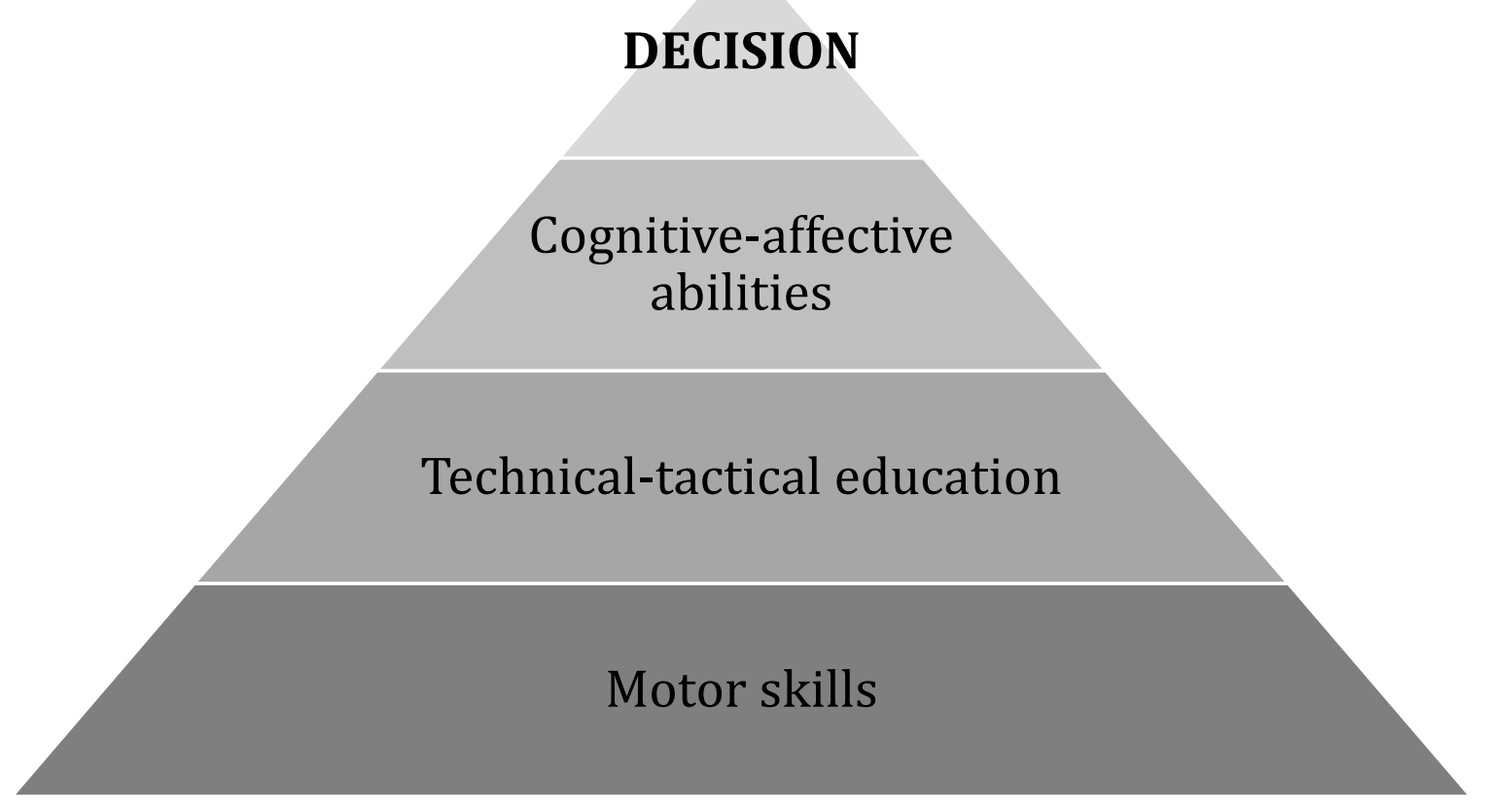

Figure 1: The conditions for making the decision (according to Balogh L., 2021)

\section{AROUSAL}

If skills game the challenge of a task, strong performance can be observed during the game. The gameplay level is related to sensorimotor abilities and cognitive difficulties (YELAMANCHILI, 2018). The relationship between arousal and performance may result in a different description depending on the performance measure (EBBECK-WEISS, 2020). Bandura and Rosenthal (1966) found some suggestive evidence that selfgenerated competing responses may mediate the disruptive effects of high arousal levels. These responses aimed to neutralize the aversiveness of the vicarious arousal situation. The results of Kerr and Cox (1990) suggest that the subjects in this study did not necessarily experience the high excparticipantent of game situations as stressful or show signs of anxiety (regardless of skill level or subsequent success). During the game, the 
winners showed slightly higher and more stable levels of excparticipantent. Cognitive participation also increases the sense of presence in the virtual reality experience. Increased feelings of presence positively influence neurophysiological arousal and attitudes towards sport (UHM et al., 2020). Allen et al. (2013) reported more significant disturbances in concentration in athletes when experiencing high levels of anxiety or high levels of happiness and less when experiencing high arousal levels. Athletes often use imagery to control their arousal levels (e.g., relaxation) (GREGG-HALL, 2007).

\section{INTELLIGENCE}

The concept of game intelligence refers to a system of cognitive abilities (BALOGHDONKA, 2020). Dynamic adaptation of behavior in an ever-changing environment is a prerequisite for achieving the overall goal. Executive functions are associated with response inhibition, multi-processing, cognitive flexibility, working memory, and creativity. They consist of separate components such as behavioral inhibition, interference control, and higher-order executive functions. The latter is closely related to the level of game intelligence (VESTBERG, 2020). Executive functions are high-level cognitive processes that are often associated with the frontal lobes. They control lowerlevel processes in the service of goal-directed behavior (FRIEDMAN-MIYAKE, 2017). (Play) intelligence is the quality of information acquisition and processing (BALOGH, 2021). In ball and team sports, it describes the ability of players to read the game, adapts quickly to changing situations, and be in the right place in a given situation. Results from Vestberg et al. (2020) suggest that either cognitive flexibility or a general increased task demand may be associated with game intelligence. High game intelligence is a fundamental psycho-physiological prerequisite for team sports (Fig 2). Balogh and Donka (2020) found a difference in stress tolerance when comparing experienced and younger team athletes based on a complex stress Holter study. Experienced athletes were less out of balance and demonstrated more stable and balanced performance. A survey by Lennartsson et al. (2015) found that cognitive, emotion-affective skills support selection and decision making; coordination and conditioning skills support execution. Ward and Williams (2013) identified anticipation, foresight, and strategic and tactical execution as components of game intelligence, alongside decision making. Thus, game intelligence is related to experience and practice and can be developed (BALOGH-DONKA, 2020). 


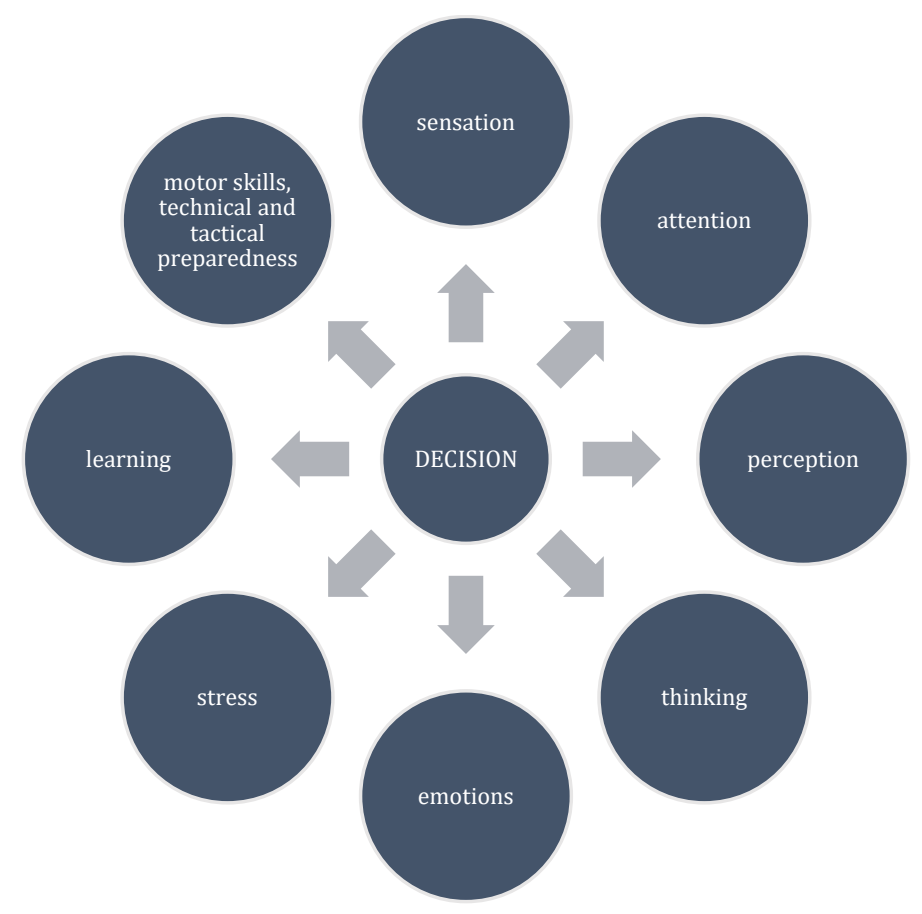

Figure 2: Components of (game) intelligence (according to Balogh-Donka., 2020)

\section{METHODS}

\section{OBJECTIVE MEASUREMENTS}

Female basketball players $(n=8)$ participated in our study. Their average age was 21.25 years. They regularly play in the Hungarian University and College National Championship, with three training sessions a week. None of the athletes reported color blindness, dyslexia and other psychiatric problems, neuropsychological deficits. All subjects were informed and gave their informed consent. The computer-assisted method was used instead of a verbal response. The subjects could view the stimuli presented on an iPad monitor and complete the touch screen tasks. Cognitive inhibition was assessed using the Color-Word Interference Test (Stroop Test); cognitive function, short-term memory, and intelligence were assessed using the Trail Making Test. Finally, we compared the scores of game statistics used in basketball and my subjective coach's opinion. We used data from three winning games and took measurements before and after games (six measurements in total), one hour before warm-ups, and immediately after games.

\section{TRAIL MAKING TEST (TMT)}

Measuring cognitive function is an increasingly important goal for clinicians and researchers. Several neuropsychological tests provide comprehensive and specific results. The Trail Making Test (Fig 3.) is a neuropsychological instrument that provides 
its user with information on a wide range of cognitive abilities (BOWIE-HARVEY, 2006). It tests short-term memory. Its primary task is to link a sequence of stimuli (numbers and letters) in a specific order as quickly as possible (REYNOLDS, 2002). In test part A, the players had to connect the numbers in ascending order from 1 to 25 points as quickly as possible and with the lowest possible error rate. In test part $\mathrm{B}$, they had to game the numbers in alphabetical order from $A$ to $L$ for 1 to 13 points: $1 \mathrm{~A}, 2 \mathrm{~B}, 3 \mathrm{C}$, etc. The time was measured to complete the task, and the number of errors was recorded. This task was the most difficult for my players. Gaudino et al. (2008) found that part B was $56 \mathrm{~cm}$ longer than part $A$ and contained more visually distracting stimuli. Their results show that Part $\mathrm{B}$ is more complex than Part A because it is a cognitive task and the increased demand for motor speed. Corrigan and Hinkeldey (1987) investigated two measures of the relationship between parts A and B of the test. They found that the difference in scores correlated with intelligence, and to a lesser extent, with age, education, and memory function. Although, like most neuropsychological tests, this one is derived from, and primarily applicable to, English speakers (BHATIA et al., 2007), my players all have a high English level, so they had no problems (because of this) with completing it.
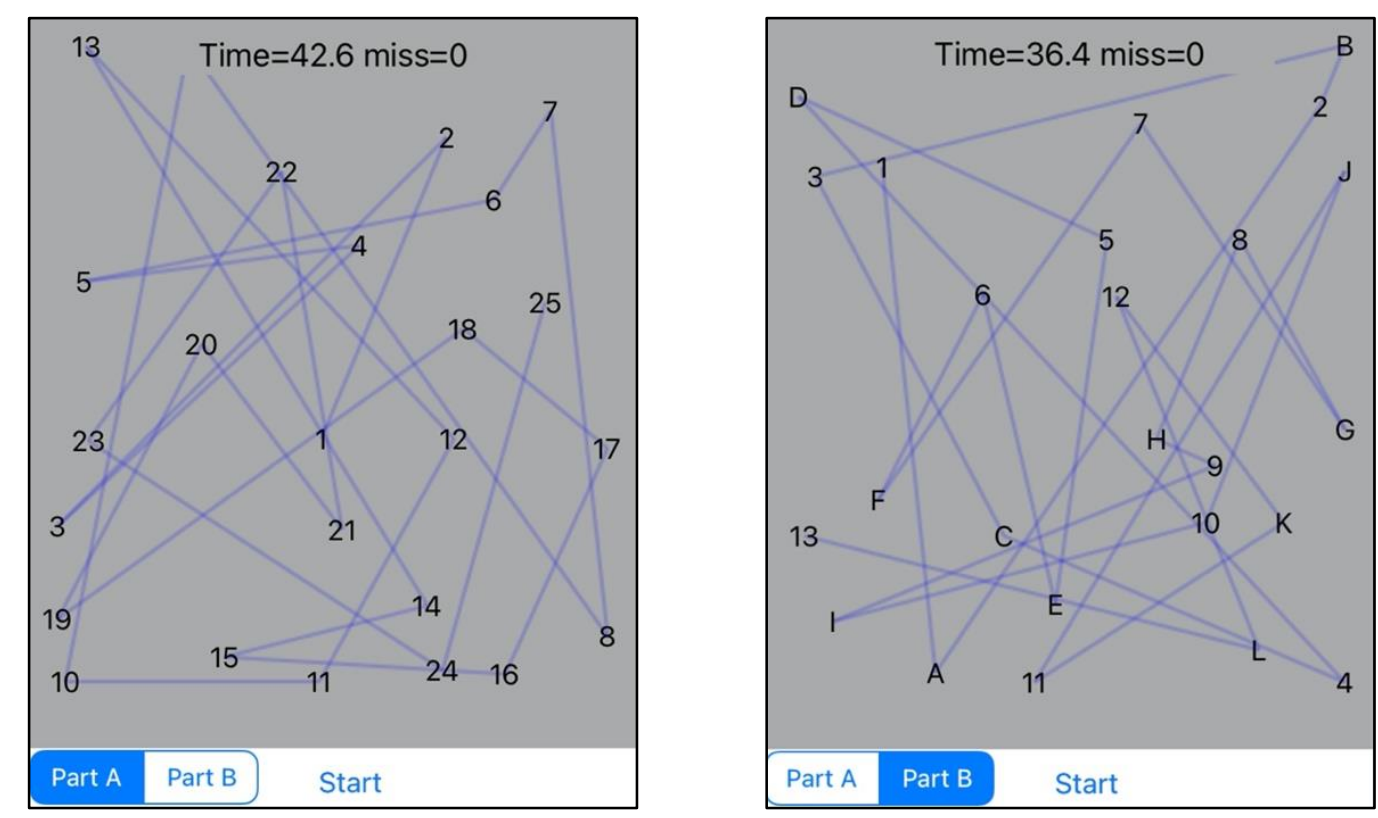

Figure 3: The interface of the TMT application (based on TMT application)

\section{COLOR-WORD INTERFERENCE TEST (CWI)}

Although considerable evidence supports the positive effects of acute exercise on cognitive inhibition, little is known about the underlying cognitive processes (HSIEH et al., 2018). The CWI (Stroop test) is a tool to assess executive function. It measures focused and selective attention, cognitive flexibility, and processing speed (Fig. 4). The CWI is able to assess the ability to inhibit irrelevant stimuli. A neuropsychological test widely used to 
assess the ability to inhibit cognitive interference, which occurs when the typical processing of a stimulus interferes with the concurrent processing of a second stimulus attribute (SCARPINA-TAGINI, 2017). It has both experimental and clinical applications. Previous literature has also found it suitable for measuring attention, processing speed, cognitive flexibility, and working memory (SCARPINA-TAGINI, 2017). In sport psychology research, the Stroop test and its derivations are commonly used to investigate the benefits of the body on cognitive function (TAKAHASHI-GROVE, 2020).

To correctly solve a task, subjects must selectively process a given visual feature that continuously blocks the automatic processing of reading (SCARPINA-TAGINI, 2017). For skilled readers, word reading is such an automated process that it is difficult for them to follow the given instruction and ignore the meaning of the word, identifying only the color of the word. The index of inhibitory control is error rate (not speed) (SCARPINA-TAGINI, 2017). In the first part, color words were presented without colors, and the word that appeared on top had to be identified from the four words below it. In the second part, the color words of the bottom row appeared, but here they were marked with different colors. The task was made more difficult because the identical word to be selected appeared in a different color. The program indicated the time and the number of errors at the end of the task.

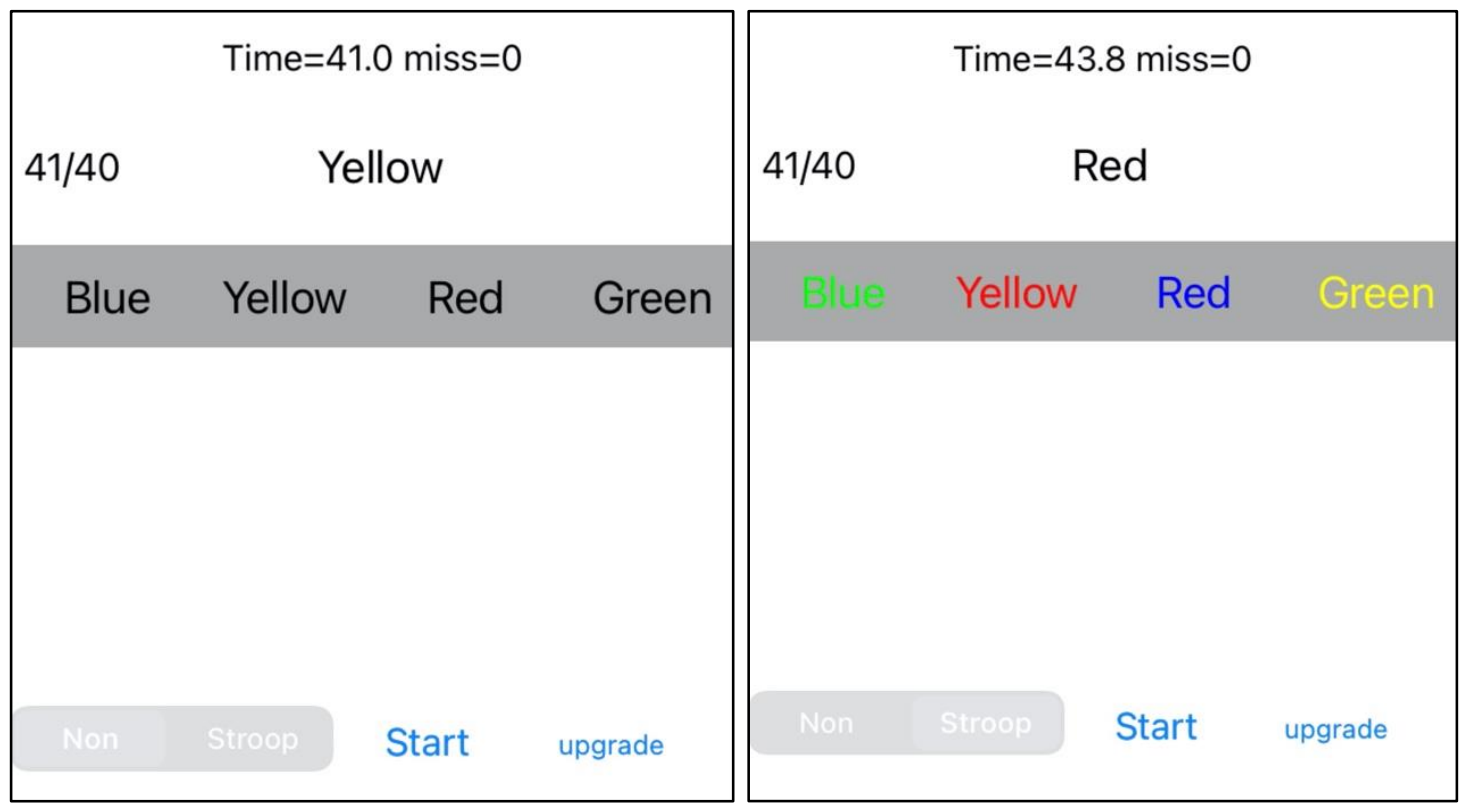

Figure 4: The interface of the CWI application (based on CWI application) 


\section{BASKETBALL STATISTICS}

In sport, you can find measurable, comparable data. Sports statistics are an indispensable and ubiquitous part of modern sports science (ÁCS-PINTÉR, 2011). It isn't easy to navigate without quantitative data, information, and measures in the world around us. Quantitative information has become so integral to our daily lives that its application has become automatic. The strategy of sport can be understood in terms of the choices made by athletes and coaches. Decision-makers must be aware of the rational structure of games; however, they must rely on limited rationality or intuition on the pitch. By describing sensible strategies, sports analytics can support better decision-making (STERBENZ et al., 2019).

In Hungary, basketball statistics indicate the time players actively play (in the quarter, half, and one-minute increments). Statistics also reflect the number and percentage of close, lay-in, inside and long-range shots, the number and efficiency of foul shots, defensive and offensive rebounds, assists, steals-turnovers and rebounds, blocks, fouls, and other mistakes (Fig. 5). The sum of these is given in an IBM indicator, which can go either positive or negative. If a player receives a value of 0 or minus, he was of no use to the team in that game. This is not entirely relevant, as these statistics are incomplete in terms of defensive rates. They do not show how many points a team gets from the opponent because of its defense rates. This is also true inversely; it cannot measure how individuals individually defend. The defensive rebounding and steals may guide this, but they do not cover the entire defensive repertoire. The number of points and assists scored is not an ideal proxy for game intelligence or success, as players playing in different positions may have other tactical goals (VESTBERG, 2020). Gooding and Gardner's (2009) results showed that the level of alertness significantly predicts the percentage of a foul shot taken. They suggested that the combination of alertness, the skill itself (practicing the foul shots), and the competitive experience contributes to predicting competitive foul shot percentage. Varca's (1980) study found that home teams significantly outperformed their opponents in terms of functionally aggressive behavior (e.g., rebounds, stripes/pokes, and blocks). He predicted that visiting teams would exhibit significantly more dysfunctional aggression (e.g., fouling). There were no significant differences between home and visitor teams in fine motor movements (e.g., lay-in, foul shots, inside and long-range shots). The behavioral dimension that distinguishes home and away games is aggressiveness. This dysfunction is more prevalent in the losing team.

A multivariate analysis by Gómez et al. (2008) showed that winning teams differ from losing teams in defensive rebounds, assists, and inside and long-range shots attempt efficiency. A shortcoming and weakness of basketball statistics may be that human resources produce them, which can sometimes be subjective and inaccurate. Also, all coaches should consider the sport goals per post, as in my opinion, the best player is not the one who scores the most points. Each position has unique expectations and characteristics; it is not by chance that we distinguish between several (1-5, quarterback, point guard, center). Today, it is possible to analyze multimedia content digitally. It is a 
Vol 4, No 1 (2021): Stadium - Hungarian Journal of Sport Sciences

https://doi.org/10.36439/shjs/2021/1/9535

constantly evolving technology, and the analysis starts with the recording of a basketball game. Rátgéber et al. (2019) set out to analyze basketball games viewed via television channels. Their study covers a wide range of activities from player identification, positioning, ball, and basket recognition to shot analysis and shot efficiency.

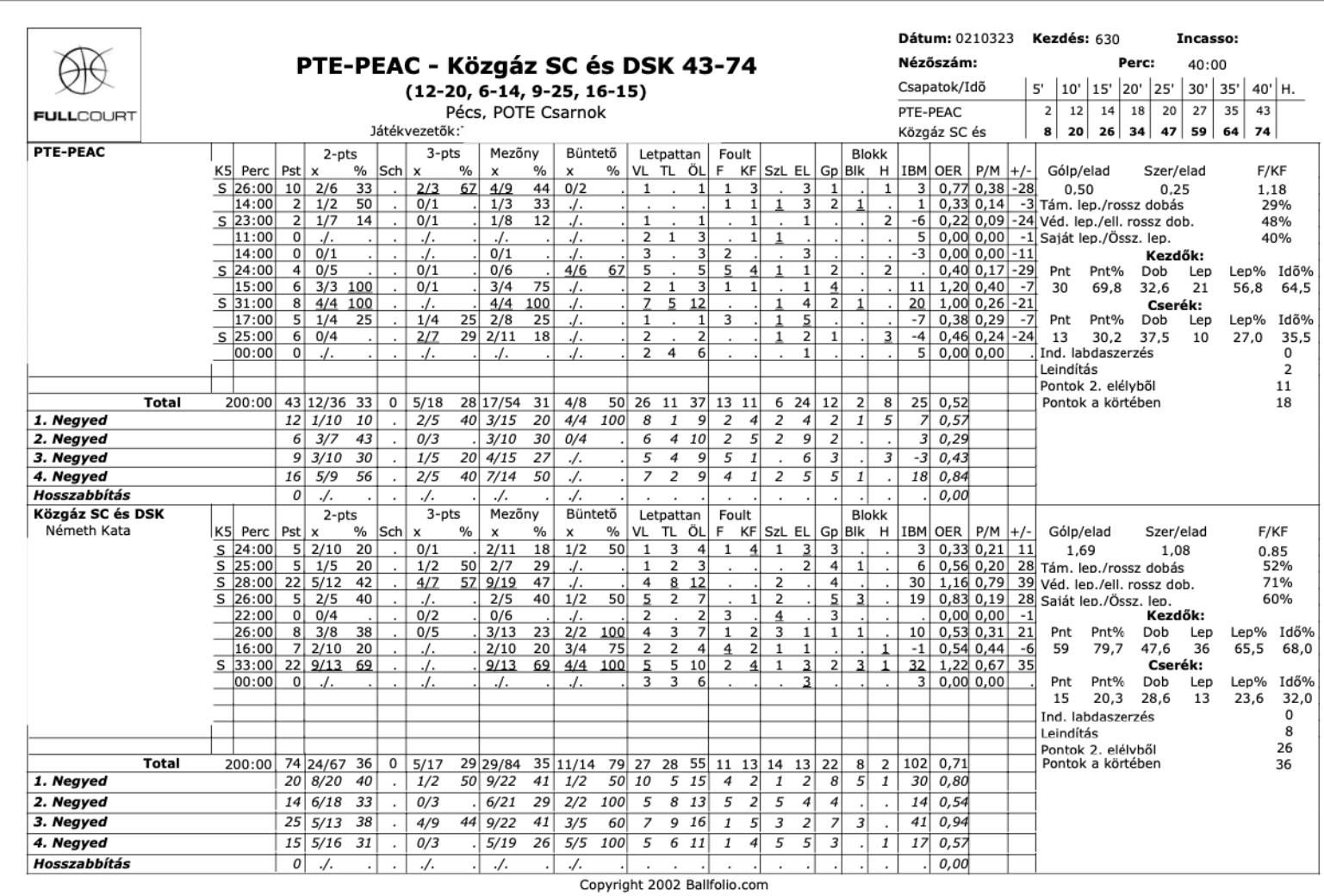

Figure 5: Basketball statistics (own data)

\section{SUBJECTIVE MEASUREMENT}

Coaching performance is based on the quality of decisions (ELSWORTHY et al., 2014). The quality of the coach's evaluation affects the player's subsequent decisions. Negative expressions lead to a refusal to accept similar situations again on the part of the players (BALOGH, 2021). Coaches need to help their players not think about their past mistakes and refrain from projecting performance consequences during the game. After errors, they should allow athletes to focus on the next play and the skills under their control (TEDESQUI-GLYNN, 2013). When giving instructions to my players, I always pay attention to its quality, regardless of the situation and my current mental state. I work with experienced, routine, adult-aged basketball players, so I do not need to point out mistakes that they already know themselves (sometimes even before making a mistake). Instead, I focus on correcting them and providing alternatives. It is up to the individual to decide what kind of communication is helpful, but I consider it a serious task and a duty to do this consistently. Coaches may face several challenges, which may include: determining what athletes need to focus on; how to focus/re-focus; how to prevent distractions; and 
delivering instructions that help athletes focus better (TEDESQUI-GLYNN, 2013). I measured each of my players' game intelligence on their subjective scale. I based it on their different mental and physical characteristics. Strength, speed, stamina, height, weight/overweight, muscle condition, technical level, attitude, diligence, will, humility, confidence, stress tolerance, attention, decision making, and tactical preparedness. The scale scores are 1- lowest possible game intelligence; 5 - average player game intelligence; 9- highest possible game intelligence. The abbreviations are the players' initials, and the numbers are my results on the subjective scale. $A D=9, E R H=8, K B K=7, A E M=8, C S D P=5$, $\mathrm{JR}=5, \mathrm{RS}=5, \mathrm{OKZ}=5 ; \mathrm{n}=8$.

\section{RESULTS}

After taking the tests several times (six times per individual), We found that they became more routine as they practiced. This saves energy that the body can use for other things. Routine has value in the game. A good indicator of the existence and quality of team play is the number of assists (the direct conversion of a pass into a goal/basket). Comparing the three games, my team has, on average more than three times as many assists as their opponents (70/22 assists). In addition, I believe rebounding played a significant role in the wins $(147 / 88$ total rebounds). Of course, basketball tactics play a role in these numbers, but so does skill. The ability to pay attention and react quickly is a prerequisite for an assist, but so is the ability to spot the player receiving the assist. When rebounding, it is necessary to correctly assess the player's position to be box out, observe his movements, and track them effectively. The players with the best results in the TMT and CWI tests (1st to 3rd place) were also among the leaders in statistical indicators (Fig. 6). The most characteristic was the rebounding numbers, IBM, and good results in the attention tests. Overall, a good performance in TMT_A, TMT_B, and CWI_A tests implies a better rebounding and thus a better IBM number. I consider my top three scorers to be intelligent team athletes, as they adapt quickly to game situations. It is also true that we are talking about experienced players who spend a lot of time on the pitch. This makes them less out of balance and more stable and balanced in their performances. They also had the highest attendance at training.

To assess the relationship between my quantitative variables and the closeness of these relationships, We intended to use Pearson correlation; and linear regression to determine the relationship between the variance of the dependent and independent variables. Due to the small number of participants, we found trend-like correlations; We could not draw significance. Therefore, we find it justified to carry out further estimations. 
Vol 4, No 1 (2021): Stadium - Hungarian Journal of Sport Sciences

https://doi.org/10.36439/shjs/2021/1/9535

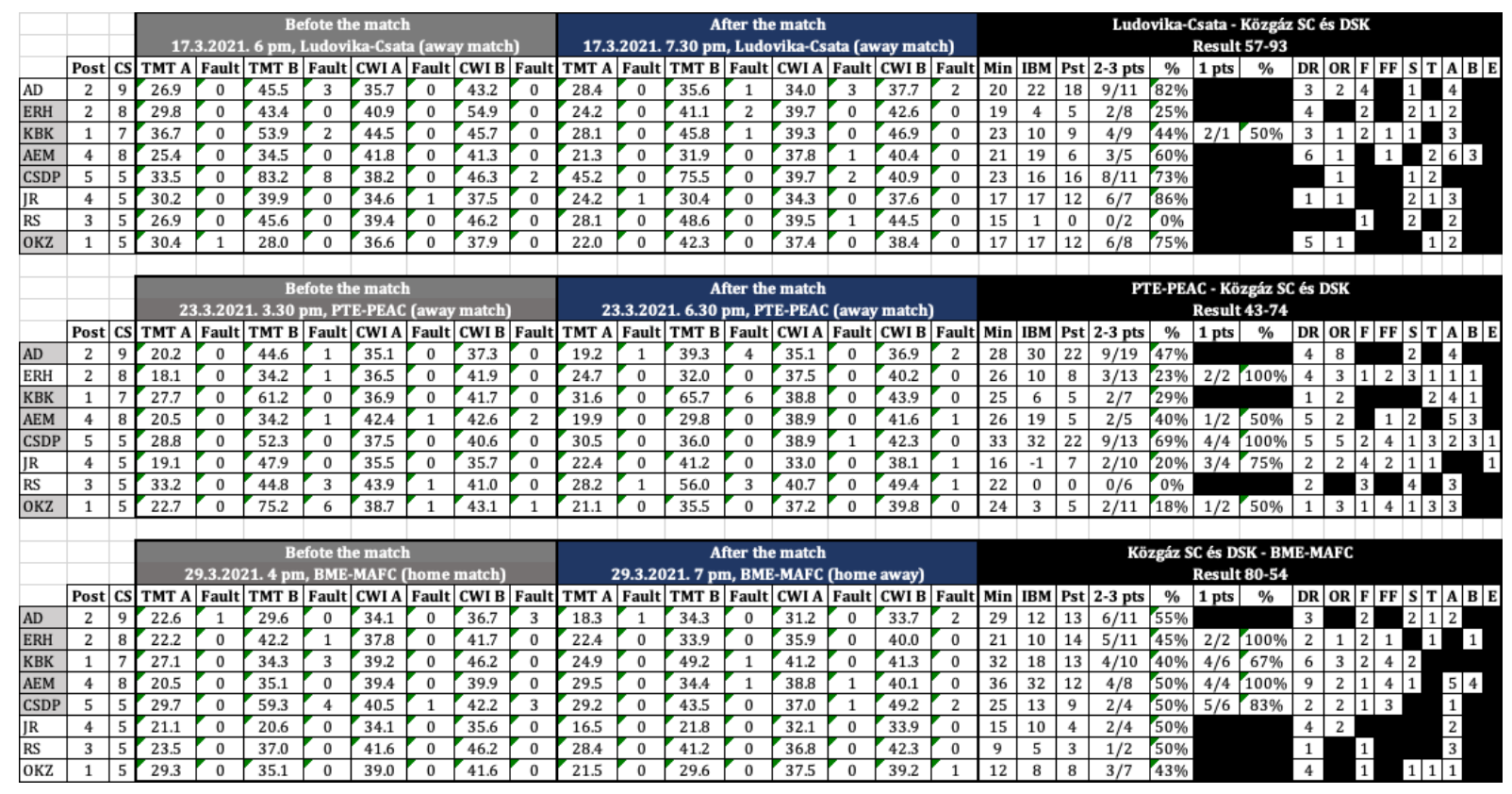

Figure 6: Results of the pre-after game and live basketball statistics (own data)

\section{DISCUSSION}

Limitations of the study include the low number of gamees and the small number of participants due to the current pandemic situation. No general conclusions can be drawn from the available data. Further studies with a more significant number of gamees, possibly including pre-and post-training measurements, are recommended.

My team's strength is in rebounding and assists. A high number of these implies teamwork, which I believe would be essential for a team sport. Compared to the statistics of our opponents, you can see that not all teams have this tactic. The number of offensive rebounds has an impact on the amount of scored shots. Both technical elements (rebounding and assists) and the number of scored shots affect the IBM indicator. To achieve a valid result, I suggest a particular statistic to record the defensive elements.

External focus improves performance in the context of well-learned skill execution. Internal focus enhances performance in the context of learning, improving and correcting new skills, and conscious practice (TEDESQUI-GLYNN, 2013).

We will continue to use the cognitive attention tests described to assess processing speed, motor speed demand, focused- and selective attention. I will also use them during training sessions, as the stress levels and influencing factors are not equal to those experienced before gamees. The different zone values are also clearly observable from the measurement numbers. Some players are motivated by stress and perform better under pressure. For others, better performance was induced when the stress was over, and the pressure was removed. The more success-oriented players in a team, the easier it is for the coach and the results. 
Another area that could be the subject of separate research is self-confidence and assertiveness, which is not an easy topic to study among athletes. The presence or absence of these concepts would also be included in assessing the overall player profile. It often makes coaches' jobs more difficult (especially if no sports psychologist is available on the basketball team).

\section{REFERENCES}

Abernethy B. (2001). Attention. In R. N. Singer, H. A. Hausenblas, \& C. M. Janelle (Eds.), Handbook of sport psychology (2nd ed., pp. 53-85). New York, NY: John Wiley.

Ács P. \& Pintér J. (2011). Bevezetés a sportstatisztikába. Dialóg Campus Kiadó

Allen M. S., Jones M., McCarthy P. J., Sheehan-Mansfield S. \& Sheffield D. (2013). Emotions correlate with perceived mental effort and concentration disruption in adult sports performers. https://doi.org/10.1080/17461391.2013.771381

Balogh L. (2021). Let's make a good decision about decision ont he court. Lecture on https://www.youtube.com/watch?v=UOFaOnsSpig\&t=230s

Balogh L. \& Donka D. B. (2020). Testing game intelligence and stress resilience inexperienced and young team athletes with VTS and innovate, complex MDE Heidelberg stress holter tools. Tanulmánykötet-Trendek a versenysport és a szabadidősport területéről, 4, University of Debrecen, 12-21.

Balogh L. (2014). To Be in the Zone - Stress and Sport Performance. DOI: 10.13140/RG.2.1.1638.6643

Balogh L. (2015). A sport és a testedzés pszichológiája - szemelvények a sportpszichológiából. Sporttudomány a mindennapos testnevelés szolgálatában. http://www.jgypk.hu/tamop13e/tananyag_html/sporttudomany/a_sport_s_a_testedzs_ pszicholgija_szemelvnyek_a_sportpszicholgibl.html

Bíró E. \& Balogh L. (2020). Officials decision-making progress in open skill sports, a systematic review. DOI: 10.36439/SHJS/2020/2/8596

Bandura A., \& Rosenthal T. L. (1966). Vicarious classical conditioning as a function of arousal level. https://doi.org/10.1037/h0022639

Bartha L. (1978). Pszichológiai alapfogalmak. ISBN 9631728528

Beilock, S. L., \& Carr, T. H. (2001). On the fragility of skilled performance: What governs choking under pressure? Journal of Experimental Psychology: General, 130(4), 701-725.

Beilock, S. L., Carr, T. H., MacMahon, C., \& Starkes, J. L. (2002). When paying attention becomes counterproductive: Impact of divided versus skill-focused at- tention on novice 
and experienced performance of sensorimotor skills. Journal of Experimental Psychology: Applied, 8(1), 6-16. doi: 10.1037//1076-898x.8.1.6.

Bhatia T., Shriharsh V., Adlakha S., Bisht V., Garg K. \& Deshpande S. N. (2007). The trail making test in India. DOI: 10.4103/0019-5545.33258

Boutcher S. H. (2008). Attentional processes and sport performance. In T. S. Horn (Ed.), Advances in sport psychology (3rd ed., pp. 325-338). Champaign, IL: Human Kinetics.

Bowie C. R. \& Harvey P. D. (2006). Administration and interpretation of the Trail Making Test. DOI: 10.1038/nprot.2006.390

Carr T. H., \& Hinckley J. J. (2012). Attention: Architecture and process. In R. K. Peach, \& L. P. Shapiro (Eds.), Cognition and acquired language disorders: An information processing approach (pp. 61-93). St. Louis, MO: Elsevier.

Corrigan J. D. \& Hinkeldey N. S. (1987). Relationships between Parts A and B of the Trail Making Test. DOI: 10.1002/1097-4679(198707)43:4<402::aidjclp2270430411>3.0.co;2-e

Ebbeck V. \& Weiss M. R. (2020). The Arousal-Performance Relationship: Task Characteristics and Performance Measures in Track and Field Athletics. https://doi.org/10.1123/tsp.2.1.13

Elsworthy N., Burke D., \& Dascombe J. B. (2014). Factors relating to the decision-making performance of Australian football officials, International Journal of Performance Analysis in Sport, 14, 2, 401-410 https://doi.org/10.1080/24748668.2014.11868730

Friedman N. P. \& Miyake A. (2017). Unity and diversity of executive functions: Individual differences as a window on cognitive structure. https://doi.org/10.1016/j.cortex.2016.04.023

Furley P. \& Memmert D. (2010). Differences in Spatial Working Memory as a Function of Team Sports Expertise: The Corsi Block-Tapping Task in Sport Psychological Assessment. https://doi.org/10.2466/pms.110.3.801-808

Gaudino E. A., Mark W. Geisler M. W. \& Squires N. K. (2008). Construct validity in the trail making test: What makes part B harder? https://doi.org/10.1080/01688639508405143

Gómez M. A., Lorenzo A., Barakat R., Ortega E. \& Palao J. M. (2008). Differences in GameRelated Statistics of Basketball Performance by Game Location for Men's Winning and Losing Teams. https://doi.org/10.2466/pms.106.1.43-50

Gooding A. \& Gardner F. L. (2009). An Investigation of the Relationship Between Mindfulness, Preshot Routine, and Basketball Free Throw Percentage. https://doi.org/10.1123/jcsp.3.4.303 
Gregg M. \& Hall C. (2007). Measurement of motivational imagery abilities in sport. https://doi.org/10.1080/02640410500386167

Hsieh Y-H., Chen K-J., Wang C-C. \& Lai C-L. (2008). Cognitive and motor components of response speed in the stroop test in Parkinson's disease patients. DOI: 10.1016/S1607551X(08)70117-7

Kennedy P., Miele D. B., \& Metcalfe J. (2013). The cognitive antecedents and motivational consequences of the feeling of being in the zone. DOI: 10.1016/j.concog.2014.07.007

Kerr H. \& Cox T. (1990). Arousal and individual differences in sport. https://doi.org/10.1016/0191-8869(91)90037-C

Laborde S. \& Raab M. (2013). The tale of hearts and reason: The influence of mood ondecision making., Journal of Sport \& Exercise Psychology, 35(4), 339-357. doi: $10.1123 /$ jsep.35.4.339

Lennartsson J., Lidström N. \& Lindberg C. (2015). Game intelligence in team sports. DOI: 10.1371/journal.pone.0125453

Matthews G. (1985). The effects of extraversion and arousal on intelligence test performance. https://doi.org/10.1111/j.2044-8295.1985.tb01971.x

McCluney E. N., McCullick B. A., \& Schempp. P. G. (2020). Factors Triggering Pressure on Basketball Coaches' In-Game Decision-Making, The Sport Journal,41, 2.

Németh K. \& Balogh L. (2020). The relationship between arousal zone, anxiety, stress and sports performance. DOI: 10.36439/SHJS/2020/2/8603

Orlick, T. (2008). In pursuit of excellence. (4th ed.). Champaign, IL: Human Kinetics.

Reynolds C. R. (2002). Comprehensive Trail-Making Test (CTMT). DOI: 10.1016/j.acn.2004.02.004

Rátgéber L., Betlehem J., Calleja-Gonzalez J. \& Ostojic S. M. (2019). Basketball for Health: Should We Hop and Shoot for a Remedy? DOI: https://doi.org/10.1016/j.mayocp.2018.11.010

Rátgéber L, Ivankovic Z., Gojkovic Z., Misolevic Z., Markoski B. \& Kostic-Zobenica A. (2019). Video Mining in Basketball Shot and Game Analysis. DOI: 10.12700/APH.16.1.2019.1.1

Scarpina F. \& Tagini S. (2017). The Stroop Color and Word Test. DOI: 10.3389/fpsyg.2017.00557

Sterbenz T., Világi K. \& Csurilla G. (2019). Sport Analytics as a tool for an effective decision making in. In: Essentials of Performance Analysis in Sport. ISBN: 9780429340130, chapter $12,12 \mathrm{p}$ 
Takahashi S. \& Grove P. M. (2020). Use of Stroop Test for Sports Psychology Study: CrossOver Design Research. DOI: 10.3389/fpsyg.2020.614038

Tedesqui R. \& Glynn B. (2013). "Focus on What?": Applying Research Findings on Attentional Focus for Elite-Level Soccer Coaching. DOI: 10.1080/21520704.2013.785453

Uhm J-P., Lee H-W. \& Han J-W. (2020). Creating sense of presence in a virtual reality experience: Impact on neurophysiological arousal and attitude towards a winter sport. https://doi.org/10.1016/j.smr.2019.10.003

Varca P. E. (1980). An Analysis of Home and Away Game Performance of Male College Basketball Teams. https://doi.org/10.1123/jsp.2.3.245

Vestberg T., Jafari R., Almeida R., Maurex L., Ingvar M. \& Petrovic P. (2020). Level of play and coach-rated game intelligence are related to performance on design fuency in elite soccer players. https://doi.org/10.1038/s41598-020-66180-w

Ward P. \& Williams A. M. (2003). Perceptual and Cognitive Skill Development in Soccer: The Multidimensional Nature of Expert Performance. DOI: 10.1123/jsep.25.1.93

Wulf, G. (2007). Attentional focus and motor learning: A review of 10 years of research. Bewegung und Training, 1-11.

Yelamanchili T. (2018). Neural correlates of flow, boredom, and anxiety in gaming: An electroencephalogram study. Missouri University of Science and Technology. 